\title{
TACTILE AND HEARING SENSITIVITY OF CHILDREN WITH AND WITHOUT AUTISM USING THE SENSORY PROFILE AND DSM-5
}

(C) by Acta Medica Saliniana ISSN $0350-364 X$

Type of manuscript: Professional papers

Title:

TACTILE AND HEARING SENSITIVITY OF CHILDREN WITH AND WITHOUT AUTISM USING THE SENSORY PROFILE AND DSM-5

Authors:

Bahira Demirović ${ }^{1}$, Amila Mujezinović ${ }^{1}$, Munevera Bećarević ${ }^{2}$

Nermin Demirovićs ${ }^{3}$ Nejra Bećarević ${ }^{2}$, Alma Dizdarević ${ }^{1}$, Vesna Bratovčić

DOI: $10.5457 / 446$

\section{Afiliations:}

${ }^{1}$ Faculty of Education and Rehabilitation, University of Tuzla, ${ }^{2}$ Faculty of Medicine, University of Tuzla, ${ }^{3}$ Institute for Special Education and Child Education Mjedenica

Received: 17.07 .2018

Corresponding author:

Bahira Demirović

bahira.demirovic@ukctuzla.ba

Background: Children with autism in their characteristics show a series of unusual reactions to stimuli in all areas of the sensory system.

Aim: The aim of this paper was to compare the tactile and auditory processes, i.e. to determine the deficits of these processes by children with autism spectrum disorder (Diagnostic and Statistical Manual of Mental Disorders, 5th ed.) in relation to children with intellectual disabilities and children of the typical population.

Methods: The sample consisted of a total of 105 children. During the survey, the method of proportional stratified sample was used and the data collection was carried out in 2017 on the entire territory of Bosnia and Herzegovina. Short Sensory Profile was applied (Dunn, 1999) and through 13 items, Tactile Perception and Hearing Perception were examined.

Results: It was found that $71.4 \%$ of children with autism had significant difficulties in the area of tactile perception and $65.7 \%$ in the area of hearing perception. Tactile and hearing sensitivity is also common by children with intellectual disabilities, which undermines the inclusion of the difficulty of sensory processing as a key diagnostic criterion for autism.

Keywords: autism, tactile sensitivity, hearing sensitivity, DSM-V.

\section{INTRODUCTION}

Everything we do requires sensory integration and when it comes to sensory data, it refers to the information that comes in tactile, vestibular, proprioceptive, auditory, visual and oral-gustatory systems (1). In one word, we can say that the world is experiencing the senses and the way in which sensory input and processing is carried out is reflected directly on our behaviour and learning.

Children with autism in their characteristics show a whole series of unusual reactions to stimuli in the area of tactile, auditory, visual and olfactory, vestibular and perceptive systems. Reports show that more than $96 \%$ of children with autism are hyper or hyposensitive in multiple domains, communication, social deficits, and sensory behavioural differences ranging from mild to severe. Although sensory hypersensitivity is not unique only to children with autism, it is more common in this population than in other populations. Studies of the comparison of the pattern of the sensory processes of children with autism or other pervasive developmental disorders with the control group of the typical population revealed the essential differences in the profile of the sensory processes of children with autism. These result clearly showed that dysfunction of sensory processes is one of the key characteristics of autism (2).

Some children with autism are described as sensitively insensitive or have a high threshold in response to stimuli (3), while they may be hypersensitive to sounds, others may look like deaf, as a consequence of the problem of sensory processing (4). Recent research has reported that a high percentage of children with autism show unusual responses to sensory experiences, compared to the responses offered by typically developing children with the same chronological age (5). These difficulties affect the entire spectrum, so that the greater the sensory dysfunction, the greater the severity of the autism symptomatology (6) and they are present from toddlers to adults (7).

The latest version of the DSM has included a typical sensory responsiveness or unusual interests in sensory aspects of the environment as one of four possible elements of which two must be met in Criterion B, which combined with persistent deficits in social communication and interaction across multiple contexts, define autism spectrum disorder (8). However, 
the enhanced or reduced response to external stimuli, as a new criterion in DSM-V for the diagnosis of autism, also occurs in intellectual and other developmental difficulties (9). This is a relatively new issue both in research and in clinical practice involving the sensory deficit of children with autism as one of the key or primary criteria for diagnosing and distinguishing from other pervasive developmental disorders.

In Bosnia and Herzegovina, there is no significant research on the tactile and hearing sensitivity of children with autism, and in this study we set out the following goal to examine the proportion of individuals with hyper- or hypo-reactivity to the sensory input of tactile and auditory inputs, in accordance with the DSM-V criterion and to determine the deficiencies of these processes by children with autism in relation to children with intellectual disabilities and children of the typical population.

\section{METHODS}

The sample of respondents consisted of children with autism, children with intellectual disabilities and children of typical development aged 3-8 year. The sample consisted of a total of 105 children divided into three groups: 35 autistic children, 35 children with intellectual disabilities, and 35 children of typical development who were included as a control sample. During the research, a proportional stratified sample method was used.

The empirical part of the study required the collection of primary data, which was done by the method of testing using the Short Sensory Profile questionnaire (10) and two sensible areas were examined through 13 items: Tactile perception (7 items) and Hearing perception (6 items). For each item, a choice of five answers on the Likert scale was used: 1-always, 2-often, 3-occasionaly, 4-rarely, 5-never. The assessment was carried out individually with each student in 2017 by observation method.

In order to respect the ethical principles of the research, during the examination, each respondent was informed in detail about the purposes of the collected data; individuals were examined only with the personal approval of the parent / guardian, and an adequate level of anonymity was ensured in order to protect their privacy. The data were collected by the method of observation of subjects during everyday activities in kindergarten or at home or during the treatment. The data collected were processed in the SPSS 20 statistical program and a single-factor analysis of ANOVA variance and the Tukey HSD test was applied.

\section{RESULTS AND DISCUSSION}

The first aim of the study was to examine the structure of tactile and hearing sensitivity of children with autism, children with intellectual disabilities, and children of typical development. This aim is realized through the analysis of a five-point scale, and we have the tables and graphs presented and explained to both coverage areas.

Table 1 presents the frequencies and percentages of the questionnaire for the area of tactile perception for all three groups of respondents.

\section{Table 1. Distribution according to tactile sensitivity}

\begin{tabular}{|c|c|c|c|c|c|c|c|}
\hline & & Always & Often & $\begin{array}{l}\text { Occasion- } \\
\quad \text { ally }\end{array}$ & Rarely & Never & Total \\
\hline & & n (\%) & n (\%) & n (\%) & n (\%) & n (\%) & n (\%) \\
\hline \multirow{3}{*}{$\begin{array}{l}\text { Expressions of trouble during } \\
\text { titivation (e.g., face washing, hair } \\
\text { cutting, nail cutting) }\end{array}$} & A & $4(11,4)$ & $14(40)$ & $11(31,4)$ & $3(8,6)$ & $3(8,6)$ & $35(100)$ \\
\hline & ID & $4(11,4)$ & $6(17,1)$ & $11(31,4)$ & $5(14,3)$ & $9(25,7)$ & $35(100)$ \\
\hline & C & $0(0)$ & $1(2,9)$ & $2(5,7)$ & $16(45,7)$ & $16(45,7)$ & 35 (100) \\
\hline \multirow{3}{*}{$\begin{array}{l}\text { Prefers wearing a long sleeve shirt } \\
\text { when it's warm and a short-sleeved } \\
\text { T-shirt when it's cold }\end{array}$} & A & $6(17,1)$ & $4(11,4)$ & $2(5,7)$ & $6(17,1)$ & $17(48,6)$ & $35(100)$ \\
\hline & ID & $2(5,7)$ & $2(5,7)$ & $4(11,4)$ & $7(20)$ & $20(57,1)$ & 35 (100) \\
\hline & $\mathrm{C}$ & $1(2,9)$ & $0(0)$ & $0(0)$ & $4(11,4)$ & $30(85,7)$ & 35 (100) \\
\hline \multirow[t]{3}{*}{$\begin{array}{l}\text { Avoids walking barefoot } \\
\text { especially on sand or grass }\end{array}$} & A & $3(8,6)$ & $3(8,6)$ & $8(22,9)$ & $8(22,9)$ & $13(37,1)$ & 35 (100) \\
\hline & ID & $5(14,3)$ & $3(8,6)$ & $3(8,6)$ & $8(22,9)$ & $16(45,7)$ & $35(100)$ \\
\hline & C & $4(11,4)$ & $0(0)$ & $0(0)$ & $16(45,7)$ & $14(40)$ & 35 (100) \\
\hline
\end{tabular}




\begin{tabular}{|c|c|c|c|c|c|c|c|}
\hline & & Always & Often & $\begin{array}{l}\text { Occasion- } \\
\text { ally }\end{array}$ & Rarely & Never & Total \\
\hline & & n $(\%)$ & $\mathrm{n}(\%)$ & $\mathrm{n}(\%)$ & $\mathrm{n}(\%)$ & $\mathrm{n}(\%)$ & $\mathrm{n}(\%)$ \\
\hline \multirow[t]{3}{*}{$\begin{array}{l}\text { Emotionally or aggressively } \\
\text { reacts to a touch }\end{array}$} & A & $1(2,9)$ & $5(14,3)$ & $8(22,9)$ & $11(31,4)$ & $10(28,6)$ & $35(100)$ \\
\hline & ID & $0(0)$ & $5(14,3)$ & $5(14,3)$ & $5(14,3)$ & $20(57,1)$ & $35(100)$ \\
\hline & $\mathrm{C}$ & $0(0)$ & $3(8,6)$ & $2(5,7)$ & $2(5,7)$ & $28(80)$ & $35(100)$ \\
\hline \multirow[t]{3}{*}{ Avoids spraying with water } & A & $1(2,9)$ & $13(37,1)$ & $8(22,9)$ & $6(17,1)$ & $7(20)$ & $35(100)$ \\
\hline & ID & $3(8,6)$ & $5(14,3)$ & $5(14,3)$ & $8(22,9)$ & $14(40)$ & $35(100)$ \\
\hline & $\mathrm{C}$ & $1(2,9)$ & $1(2,9)$ & $1(2,9)$ & $12(34,3)$ & $20(57,1)$ & $35(100)$ \\
\hline \multirow[t]{3}{*}{$\begin{array}{l}\text { Has difficulty standing in line } \\
\text { or close to other people }\end{array}$} & A & $4(11,4)$ & $15(42,9)$ & $7(20)$ & $4(11,4)$ & $5(14,3)$ & $35(100)$ \\
\hline & ID & $1(2,9)$ & $6(17,1)$ & $9(25,7)$ & $5(14,3)$ & $14(40)$ & $35(100)$ \\
\hline & $\mathrm{C}$ & $0(0)$ & $0(0)$ & $2(5,7)$ & $1(2,9)$ & $32(91,4)$ & $35(100)$ \\
\hline \multirow[t]{3}{*}{$\begin{array}{l}\text { Rubs or scratches the place where } \\
\text { he/she was touched }\end{array}$} & A & $5(14,3)$ & $6(17,1)$ & $9(25,7)$ & $3(8,6)$ & $12(34,3)$ & $35(100)$ \\
\hline & ID & $2(5,7)$ & $0(0)$ & $9(25,7)$ & $5(14,3)$ & $19(54,3)$ & $35(100)$ \\
\hline & $\mathrm{C}$ & $0(0)$ & $1(2,9)$ & $2(5,7)$ & $3(8,6)$ & $29(82,9)$ & $35(100)$ \\
\hline
\end{tabular}

Legend: A- children with autism, ID- children with intellectual disabilities and C-control group

By analysing the total response pool for tactile perception of children with autism, the highest percentage of responses consisted of answers for never $27.3 \%$, often $24.5 \%$, occasionally $21.6 \%$, rarely $16.7 \%$, and the answer always as the lowest response respondents chose $9.8 \%$. By children with intellectual disabilities, the highest percentage of responses consisted in the answer never $45.7 \%$, then occasionally $18.8 \%$, rarely $17.6 \%$, often $11 \%$, and the answer always was the answer that the respondents least selected $6.9 \%$, while by children of typical developmental, the highest percentage of responses is never 69\%, then rarely $22 \%$, occasionally $4.1 \%$, often and always
$2.4 \%$. By analysing the response to tactile perception, we can notice that children with autism had the most pronounced difficulties on variables „Prefers wearing a long sleeve shirt when it's warm and a short-sleeved T-shirt when it's cold“, „Rubs or scratches the place where he/she was touched“, „Expressions of trouble during titivation (e.g., face washing, hair cutting, nail cutting)“, and „Has difficulty standing in line or close to other people".

By children with intellectual disabilities, difficulties are most pronounced on variables „Expressions of trouble during titivation (e.g., face washing, hair cutting, nail cutting)“ and „Has difficulty standing in line or close to

Table 2. Descriptive data for the area of tactile sensitivity

\begin{tabular}{|l|c|c|c|c|c|}
\hline \multicolumn{1}{|c|}{ Subsamples } & $\mathrm{N}$ & Minimum & Maximum & $\begin{array}{c}\text { Arithmetic } \\
\text { mean }\end{array}$ & $\begin{array}{c}\text { Standard } \\
\text { deviation }\end{array}$ \\
\hline Children with autism & 35 & 13 & 34 & 22,91 & 5,506 \\
\hline $\begin{array}{l}\text { Children with } \\
\text { intellectual disabilities }\end{array}$ & 35 & 16 & 35 & 26,89 & 5,661 \\
\hline Children of typical development & 35 & 20 & 35 & 31,69 & 3,350 \\
\hline Total & 35 & 13 & 35 & 27,16 & 4,839 \\
\hline
\end{tabular}


other people" while by children of typical development the greatest difficulties can be noticed on the particle „Avoids walking barefoot especially on sand or grass“, which can be brought in the context of the modern overstretching attitude of the parents.
Table 2 gives the descriptive attitudes of the respondents' views on the Short Sensory Profile: the number of respondents in the group $(\mathrm{N})$, minimum, maximum, the arithmetic mean, and the standard deviation, where the lower results indicate higher sensitivity.

Table 3. Collective data for the area of tactile sensitivity

\begin{tabular}{|l|c|c|c|c|}
\hline \multicolumn{1}{|c|}{ Subsamples } & $\begin{array}{c}\text { Typical } \\
\text { characteristics }\end{array}$ & $\begin{array}{c}\text { Probable } \\
\text { difference }\end{array}$ & $\begin{array}{c}\text { Significant } \\
\text { difference }\end{array}$ & Total \\
\hline & $20-15$ & $14-12-4$ & $\mathrm{n}(\%)$ \\
\hline Children with autism & $\mathrm{n}(\%)$ & $\mathrm{n}(\%)$ & $\mathrm{n}(\%)$ & $35(100)$ \\
\hline $\begin{array}{l}\text { Children with } \\
\text { intellectual disabilities }\end{array}$ & $5(14,3)$ & $5(14,3)$ & $17(48,6)$ & $35(100)$ \\
\hline Children of typical development & $27(77,1)$ & $6(17,2)$ & $2(5,7)$ & $35(100)$ \\
\hline
\end{tabular}

Table 3 presents frequencies and percentage deviations in relation to the normal range (typical characteristics) for the area of tactile perception. Analyzing the results of a group of children with autism of 25 subjects (71.4\%), a significant difference was found, i.e. the achieved score ranges from 7 to 26 . In 5 respondents (14.3\%), a probable difference was determined, i.e. the score is in the range of 27 to 29, while the score of 5 subjects is between 30 and 35 , which represents typical characteristics.

By 17 subjects with intellectual disabilities (48.6\%), a significant difference was identified according to instrument standards and classification of raw scores, i.e. the achieved score ranges from 7 to 26 . By 5 respondents (14.3\%), a probable difference was determined, i.e. the score is in the range of 27 to 29 , while the score of 13 examinees ranges from 30 to 35 , which represents typical characteristics.

Analyzing the results of a group of children of typical development (2 subjects) (5.7\%), a significant difference was found, i.e. the score is in the range of 7 to 26 . By 6 subjects (17.2\%), a probable difference was determined, i.e. the score is in the range of 27 to 29 , while the score of 27 examinees ranges from 30 to 35 , which represents typical characteristics.

Table 4. Distribution according hearing sensitivity

\begin{tabular}{|l|c|c|c|c|c|c|c|}
\hline & & Always & Often & $\begin{array}{c}\text { Occasion- } \\
\text { ally }\end{array}$ & Rarely & Never & Total \\
\hline & & $\mathrm{n}(\%)$ & $\mathrm{n}(\%)$ & $\mathrm{n}(\%)$ & $\mathrm{n}(\%)$ & $\mathrm{n}(\%)$ & $\mathrm{n}(\%)$ \\
\hline $\begin{array}{l}\text { If a lot of noise is present he/she } \\
\text { is disturbed or has problems in } \\
\text { functioning }\end{array}$ & $\mathrm{A}$ & $6(17,1)$ & $7(20)$ & $9(25,7)$ & $4(11,4)$ & $9(25,7)$ & $35(100)$ \\
\hline & ID & $4(11,4)$ & $8(22,9)$ & $10(28,6)$ & $3(8,6)$ & $10(28,6)$ & $35(100)$ \\
\hline $\begin{array}{l}\text { He/she does not seem to hear what is } \\
\text { being said to him (he does not turn on } \\
\text { when you speak, he ignores you) }\end{array}$ & A & $8(22,9)$ & $9(25,7)$ & $6(17,1)$ & $6(17,1)$ & $6(17,1)$ & $35(100)$ \\
\hline & ID & $2(5,7)$ & $7(20)$ & $14(40)$ & $6(17,1)$ & $6(17,1)$ & $35(100)$ \\
\hline $\begin{array}{l}\text { Cannot work with background noise } \\
\text { (fan, air conditioning) }\end{array}$ & A & $4(11,4)$ & $3(8,6)$ & $14(40)$ & $5(14,3)$ & $9(25,7)$ & $35(100)$ \\
\hline & ID & $4(11,4)$ & $3(8,6)$ & $10(28,6)$ & $4(11,4)$ & $14(40)$ & $35(100)$ \\
\hline
\end{tabular}




\begin{tabular}{|l|c|c|c|c|c|c|c|}
\hline & & Always & Often & $\begin{array}{c}\text { Occasion- } \\
\text { ally }\end{array}$ & Rarely & Never & Total \\
\hline & & $\mathrm{n}(\%)$ & $\mathrm{n}(\%)$ & $\mathrm{n}(\%)$ & $\mathrm{n}(\%)$ & $\mathrm{n}(\%)$ & $\mathrm{n}(\%)$ \\
\hline $\begin{array}{l}\text { Has a problem solving a task } \\
\text { when the radio is on }\end{array}$ & $\mathrm{A}$ & $3(8,6)$ & $3(8,6)$ & $14(40)$ & $5(14,3)$ & $10(28,6)$ & $35(100)$ \\
\hline & ID & $3(8,6)$ & $5(14,3)$ & $7(20)$ & $5(14,3)$ & $15(42,9)$ & $35(100)$ \\
\hline & $\mathrm{C}$ & $2(5,7)$ & $0(0)$ & $4(11,4)$ & $7(20)$ & $22(62,9)$ & $35(100)$ \\
\hline $\begin{array}{l}\text { He does not answer when someone } \\
\text { calls his name, but you are sure his }\end{array}$ & $\mathrm{A}$ & $5(14,3)$ & $9(25,7)$ & $8(22,9)$ & $6(17,1)$ & $7(20)$ & $35(100)$ \\
\hline & ID & $3(8,6)$ & $4(11,4)$ & $14(40)$ & $7(20)$ & $7(20)$ & $35(100)$ \\
\hline & C & $0(0)$ & $1(2,9)$ & $3(8,6)$ & $8(22,9)$ & $23(65,7)$ & $35(100)$ \\
\hline $\begin{array}{l}\text { There are difficulties } \\
\text { in maintaining attention }\end{array}$ & A & $14(40)$ & $8(22,9)$ & $5(14,3)$ & $2(5,7)$ & $6(17,1)$ & $35(100)$ \\
\hline & ID & $10(28,6)$ & $8(22,9)$ & $9(25,7)$ & $3(8,6)$ & $5(14,3)$ & $35(100)$ \\
\hline & C & $0(0)$ & $2(5,7)$ & $5(14,3)$ & $4(11,4)$ & $24(68,6)$ & $35(100)$ \\
\hline
\end{tabular}

Legend: A- children with autism, ID- children with intellectual disabilities and C-control group

By analyzing the overall collection of answers for the area of hearing perception of children with autism, the highest percentage of responses consisted of answers occasionally $26.7 \%$, then responses never $22.4 \%$, always $19 \%$ and often $18.6 \%$ and the answer rarely had the lowest score that the respondents chose $13.3 \%$. By children with intellectual disabilities, the highest response rate is occasionally $30.5 \%$ then never $27.1 \%$, often $16.7 \%$, rarely $13.3 \%$, and then the answer always as the lowest response. By children of typical development, the highest percentage of responses is never $64.8 \%$, followed by rarely $18.6 \%$, occasionally $11.4 \%$, often $3.8 \%$ and always $1.4 \%$.

By analyzing the response in the field of hearing perception, we can notice that children with autism had the most pronounced difficulties on particles „There are difficulties in maintaining attention" with percentage of $40 \%$ "always" responses, „He/she does not seem to hear what is being said to him (he does not turn on when you speak, he ignores you) " with percentage of $22,9 \%$ "always” responses and „He does not answer when someone calls his name, but you are sure his hearing is okay" with percentage of 14,3\% "always" responses. By children with intellectual disabilities the most varied difficulties are on particles „There are difficulties in maintaining attention "with percentage of $28,6 \%$ "always" responses and „If a lot of noise is present he/ she is disturbed or has problems in functioning" with percentage of $11,4 \%$ "always" responses. While by children of typical development the greatest difficulties can be noticed on the particle „Has a problem solving a task when the radio is on "with percentage of 5,7\% "always" responses.

Table 5. Descriptive data for the area of hearing sensitivity

\begin{tabular}{|l|c|c|c|c|c|}
\hline \multicolumn{1}{|c|}{ Subsamples } & $\mathrm{N}$ & Minimum & Maximum & $\begin{array}{c}\text { Arithmetic } \\
\text { mean }\end{array}$ & $\begin{array}{c}\text { Standard } \\
\text { deviation }\end{array}$ \\
\hline Children with autism & 35 & 10 & 29 & 18,09 & 4,990 \\
\hline $\begin{array}{l}\text { Children with } \\
\text { intellectual disabilities }\end{array}$ & 35 & 9 & 28 & 19,57 & 4,698 \\
\hline Children of typical development & 35 & 19 & 30 & 26,49 & 4,111 \\
\hline Total & 105 & 9 & 30 & 21,38 & 4,599 \\
\hline
\end{tabular}

Table 5 gives the descriptive data of the respondents' views on the Short Sensory Profile Questionnaire: the number of respondents in the group $(\mathrm{N})$, minimum, maximum, the arithmetic mean, and the standard deviation. 
Table 6. Collective data for the area of hearing sensitivity

\begin{tabular}{|l|c|c|c|c|}
\hline \multicolumn{1}{|c|}{ Subsamples } & $\begin{array}{c}\text { Typical } \\
\text { characteristics }\end{array}$ & $\begin{array}{c}\text { Probable } \\
\text { difference }\end{array}$ & $\begin{array}{c}\text { Significant } \\
\text { difference }\end{array}$ & Total \\
\hline & $20-15$ & $14-12$ & $11-4$ & \\
\hline Children with autism & $\mathrm{n}(\%)$ & $\mathrm{n}(\%)$ & $\mathrm{n}(\%)$ & $\mathrm{n}(\%)$ \\
\hline $\begin{array}{l}\text { Children with } \\
\text { intellectual disabilities }\end{array}$ & $7(20)$ & $5(14,3)$ & $23(65,70)$ & $35(100)$ \\
\hline Children of typical development & $8(22,9)$ & $8(22,9)$ & $19(54,20)$ & $35(100)$ \\
\hline
\end{tabular}

By analyzing the obtained scores in Table 6, the frequencies and percentage deviations relative to the normal range (typical characteristics) for the hearing perception are presented.

By 23 subjects with autism (65.7\%), a significant difference was found, i.e. the achieved score is in the range of 6 to 19 according to instrument norms of typical performance. By 5 respondents (14.3\%), a probable difference was determined, i.e. the score is in the range of 20 to 22 , while the score of 7 examinees ranges between 23 and 30, which represents typical characteristics. By 19 subjects with intellectual disabilities $(54.2 \%)$, a significant difference was determined, i.e. the score is in the range of 6 to 19. By 8 subjects (22.9\%), a probable difference is determined, i.e. the score is in the range of 20 to 22, while the score of 8 examinees ranges between 23 and 30 , which represents typical characteristics. By 5 typical development respondents (14.3\%), a significant difference was found, i.e. the achieved score is in the range of 6 to 19. In the case of 2 respondents (5.7\%), a probable difference was determined, i.e. the score is in the range of 20 to 22 , while the score of 28 subjects ranges between 23 and 30, which represents typical characteristics.

With single-factor analysis in relation to the type of difficulties of children in the area of hearing perception, the largest statistically significant difference was found at the level of $p<0,05: F=33,029$ with $p=0,0001$. By analyzing the descriptive data for this area, it is notable that the arithmetic mean of attitudes of children with autism is 18,09 , the arithmetic mean of children with intellectual disabilities is 19,57, and the arithmetic mean of children of typical development is 26,49 , which indicates that children with autism have the greatest deficit. In the area of tactile perception, a statistically significant difference was found at $p<0.05: F=27.528$ with $p=0.0001$. By analysing the descriptive data for this area, it is notable that the arithmetic mean for children with autism is 22.91, the arithmetic mean for children with intellectual disabilities is 26.89, and the arithmetic mean for children of typical development is 31.69, which indicates that autistic children have the biggest deficit in the area of tactile perception. By using a post hoc test, the Tukey HSD test statistical significance was established between the group of children with disorder of autism spectrum and children of typical development ( $F=44,200, p=0.000)$, as well as the group of children with intellectual disabilities and children of typical development $(F=35,829, p=0.000)$. In the case of children with autism, the greatest deficit of the observed processes was determined in relation to children with intellectual disabilities $(C F=44,200, p=$ 0.000. and children of typical development $(F=35,829$, $p=0.000$ ).

\section{DISCUSSION}

Similar results were found in the study of the sensory processes of children with autism and children of typical development, where it was found that $95 \%$ of children with autism vs. $16.8 \%$ of children of typical development show certain difficulties in the sensory processes (11). Furthermore, Dalgrin and Gillberg state that sensitivity to childhood stimulus is a powerful discriminator between children with and without autism (12). Some earlier studies by Ornitz and associates point out that sensory modulation affects more than $70 \%$ of children under 6 years of age with autism, as confirmed by our research $(13,14)$. Similar data, including no sound response $(81 \%)$ and sensitivity to loud sounds (53\%) were received by Volkmar and associates (15).

On the other hand, children with autism do not differ much from children with intellectual disabilities, where we can see that both groups have much more symptoms of tactile and hearing sensitivity than children of typical development. However, McCormick et al (7) state that children with autism have much more severe hearing difficulties than children with other developmental difficulties. The results of the cross-sectional study suggest that children with autism and ADHD show similarities in sensory processing patterns (i.e., avoiding, sensitivity, registration, seeking), which were elevated as compared to a typical development group. With regard to sensory systems, children with autism showed the highest rate of oral processing differences, followed by ADHD and typical development (5). Compared to the children with other developmental disabilities more children with autism scored within the definite difference range on at least one hyperreactive domain on the SSP (Short Sensory profile). Hyper-reactivity to the sensory environment was more 
common among the autism group compared to the children with other developmental disabilities group for tactile, taste/ smell and visual/auditory sensitivity. Regarding hyposensitivity, a greater proportion of the autism group compared to the children with other developmental disabilities group, scored within the definite difference on the SSP auditory filtering subscale (9). Linke et al. examined the relationship between auditory processing, interhemispheric and thalamocortical network connectivity on a sample of 40 children with autism and 38 children of typical development, and the severity of symptoms of social behaviour (16). They found that atypical sound processing is associated with social, cognitive, and communicative impairments. In addition, the weight of the debilitating sensory process and lower verbal IQ were associated with decreased interhemispheric connectivity of auditory cortices in autism.

\section{CONCLUSION}

The results of our research indicate that in the case of children with autism, a statistically significant deficit of

\section{REFERENCES}

1. Mamić D, Fulgosi-Masnjak R. Stimulation of Sensory Integration of Students with Autism by Hearing Integration Training - Mozart Effect. Croatian magazine for rehabilitation research 2010; 46 (1): 57-68.

2. Baranek GT, David FJ, Poe MD, Stone WL, Watson LR. Sensory experiences questionnaire: Discriminating sensory features in young children with autism, developmental delays, and typical development. Journal of Child Psychology and Psychiatry 2006; 47(6):591601.

3. Watling RI, Deitz J, White O. Comparison of Sensory Profile Scores of Young Children with and without Autism Spectrum Disorders', American Journal of Occupational Therapy 2001; 55(4):416-23.

4. Frith U. Autism: Explaining the Enigma. 1992. Oxford: Blackwell.

5. Little LM, Dean E, Tomchek S, Dunn W. Sensory Processing Patterns in Autism, Attention Deficit Hyperactivity Disorder, and Typical Development. Physical \& Occupational Therapy In Pediatrics. 2017; 38(3):243-254.

6. Sanz-Cervera P, Pastor-Cerezuela G, Fernández-Andrés MI, Tárraga-Mínguez R. Sensory processing in children with autism spectrum disorder: relationship with non-verbal IQ, autism severity and attention deficit/ hyperactivity disorder symptomatology. Res Dev Disabil 2015; 45: 188-201.

7. McCormick C, Hepburn S, Young GS, Rogers SJ. Sensory symptoms in children with autism spectrum disorder, other developmental disorders and typical development: A longitudinal study. Autism 2016; 20(5): 572-579. the observed processes was found in relation to children with intellectual disabilities and children of typical development. It was found that $71.4 \%$ of children with autistic spectrum disorders have significant difficulties in the area of tactile perception and $65.7 \%$ in the area of hearing perception, compared to $48.6 \%$ and $54.2 \%$ of children with intellectual disabilities. This result does not differ from the results achieved in other studies. Also, qualitative analysis indicates very similar difficulties of tactile and hearing sensitivity between the two observed groups of children with developmental disabilities. Our results support the inclusion of tactile and hearing sensitivity as an atypical sensory response to injection from the environment in the DSM-V diagnostic criteria, but also emphasize that they are not unique to children with autism in relation to intellectual disabilities. This requires great caution when setting diagnosis and it is still recommended that other characteristics of autism have to be taken into account during clinical identification and treatment itself. We can conclude that dysfunction of sensory integration cannot be taken as a key diagnostic criterion, but rather as an additional criterion in diagnosing autism.

8. American Psychiatric Association. Diagnostic and Statistical Manual of Mental Disorders. 5th ed. Arlington, TX: American Psychiatric Publishing 2013.

9. Green D, Chandler D, Charman T, Simonoff E, Baird G. Brief Report: DSM-5 Sensory Behaviours in Children With and Without an Autism Spectrum Disorder. J Autism Dev Disord 2017; 11:20.

10. Dunn W. Sensory Profile Manual. San Antonio, TX: Psychological Corporation 1999.

11. Tomchek SD, Dunn W. Sensory processing in children with and without autism: A comparative study using the Short Sensory Profile.American Journal of Occupational Therapy 2007; 61:190-200.

12. Dahlgren SO, Gillberg C. Symptoms in the first two years of life: a preliminary population study of infantile autism. European Archives of Psychiatry and Neurological Sciences 1989; 238: 169-174.

13. Ornitz EM, Guthrie D, Farley AH. The early development of autistic children. Journal of Autism and Developmental Disorders 1977; 7: 207-229.

14. Ornitz EM, Guthrie D, Farley AH. The early symptoms of childhood autism. In G. Sherban (Ed.), Cognitivedefects in the development of mental illness. 1978 New York: Brunner/Mazel.

15. Volkmar FR, Cohen DJ, Paul R. An evaluation of DSM-III criteria for infantile autism. Journal of the AmericanAcademy of Child Psychiatry. 1986; 25: 190-197.

16. Linke AC, Jao Keehn RJ. Pueschel EB, Fishman I, Müller RA. Children with ASD show links between aberrant sound processing, social symptoms, and atypical auditory interhemispheric and thalamocortical functional connectivity. Developemntal Cognitive Neuroscience 2018; 29: 117-126. 